\title{
Foreword-Special Issue on Advances in Logistics and Supply Chain Management
}

\author{
Huynh Trung Luong* \\ Asian Institute of Technology School of Engineering and Technology Industrial System Engineering Program \\ P.O. Box 4 Klong Luang, Pathumthani 12120 Thailand \\ * Corresponding Author, E-mail: luong@ait.ac.th
}

The Asia Pacific Industrial Engineering and Management Systems (APIEMS) Conferences are annual conferences organized by the Asia Pacific Industrial Engineering and Management Society. The core value of APIEMS is associating and exchanging the better industrial engineering education, researches, and exchange information from different countries. Since the first APIEMS conference organized in 1998 in Beijing, China, APIEMS has rapidly emerged as an important forum for exchange of ideas and information about latest developments in the field of industrial engineering and management system among professionals from Asia-Pacific countries.

The 13th Asia Pacific Industrial Engineering and Management Systems Conference (APIEMS2012) was held on December 02-05, 2012 in Phuket City, the capital of the biggest island located in the Andaman Sea of southern Thailand which is also a very famous touristical city. The conference, which covers a wide range of topics in response to the conference theme of "Achieving Sustainability through Effective Resource Management", successfully provided a forum for researchers, university lecturers and engineers to communicate on their latest achievements in the field of industrial engineering and management systems and to seek for future collaboration.

In this special issue of the Industrial Engineering and Management Systems Journal (IEMS), five papers were selected among more than 250 submitted papers to the conference after a usual reviewing process in accordance with the rigorous standards of the journal.

The first paper by Rusman and Shimizu investigates the effect of continuity rate under disruption risk on the performance of multistate logistic network. Mixed-integer programming technique is employed to help design the resilient multistate logistic network in this paper. The second paper by Saithong and Luong studies a supply chain contract with put and call options between a distributor and a supplier taking into consideration the effect of nonlinear option premium price on the ability of the contract to help coordinate the supply chain. The third paper by Koide and Sandoh mathematically analyses the effect of consumer's reference price on multi-period inventory clearance pricing policy to help determine the optimal sales price so as to maximize the expected profit. In the fourth paper, Ohmori and Yoshimoto propose a framework to help manage supply chain disruption risks by utilizing network reliability theory. Three risk mitigation approaches are also proposed the help mitigate the risks from natural disasters or other high impact risk drivers. Last but not least, Takemoto et al. examines the use of Akaike information criterion in control chart to help detect the parameters which are responsible for out-of-control condition of manufacturing processes.

As guest editor for this special issue, I would like to thank the authors for their contributions and the reviewers for their time that helped improve the quality of this issue. I would like to specially thank the editor-in-chief of IEMS, Prof. Mitsuo Gen, for giving me the opportunity to publish selected papers as a special issue of the journal. I would also like to thank the managing editor, Prof. Chi-Hyuck Jun, for guiding me through the editorial process. It was a pleasure to take part in this special issue for Industrial Engineering and Management Systems Journal. 